\title{
Cardiometabolic Risk in US Army Recruits and the Effects of Basic Combat Training
}

\author{
Stefan M. Pasiakos ${ }^{19}$, J. Philip Karl ${ }^{19}$, Laura J. Lutz ${ }^{1}$, Nancy E. Murphy ${ }^{1}$, Lee M. Margolis ${ }^{1}$, Jennifer C. \\ Rood $^{2}$, Sonya J. Cable ${ }^{3}$, Kelly W. Williams ${ }^{3}$, Andrew J. Young ${ }^{1}$, James P. McClung ${ }^{1 *}$
}

1 Military Nutrition Division, United States Army Research Institute of Environmental Medicine, Natick, Massachusetts, United States of America, 2 Pennington Biomedical Research Center, Louisiana State University System, Baton Rouge, Louisiana, United States of America, 3 Directorate of Basic Combat Training, Fort Jackson, South Carolina, United States of America

\begin{abstract}
Background: Cardiometabolic disease risk in US military recruits and the effects of military training have not been determined. This study examined lifestyle factors and biomarkers associated with cardiometabolic risk in US Army recruits (209; 118 male, 91 female, $23 \pm 5$ yr) before, during, and after basic combat training (BCT).

Methodology/Principal Findings: Anthropometrics; fasting total (TC), high-density lipoprotein (HDL) and low-density lipoprotein (LDL) cholesterol; triglycerides (TG); glucose; and insulin were measured at baseline and every 3 wks during the 10 wk BCT course. At baseline, $14 \%$ of recruits were obese $\left(\mathrm{BMI}>30 \mathrm{~kg} / \mathrm{m}^{2}\right), 27 \%$ were cigarette smokers, $37 \%$ were sedentary, and $34 \%$ reported a family history of cardiometabolic disease. TC was above recommended levels in $8 \%$, LDL in $39 \%$, TG in $5 \%$, and glucose in $8 \%$ of recruits, and HDL was below recommended levels in $33 \%$ of recruits at baseline. By week 9, TC decreased 8\%, LDL 10\%, TG 13\%, glucose 6\% and homeostasis model assessment of insulin resistance (HOMA-IR) $40 \%$ in men $(P<0.05)$. In women, TC, LDL, glucose and HOMA-IR were decreased from baseline at weeks 3 and $6(P<0.05)$, but were not different from baseline levels at week 9 . During $B C T$, body weight declined in men but not women, while body fat percentage declined in both men and women $(P<0.05)$.
\end{abstract}

Conclusions/Significance: At the start of military service, the prevalence of cardiometabolic risk in US military recruits is comparable to that reported in similar, college-aged populations. Military training appears to be an effective strategy that may mitigate risk in young people through improvements in lipid profiles and glycemic control.

Citation: Pasiakos SM, Karl JP, Lutz LJ, Murphy NE, Margolis LM, et al. (2012) Cardiometabolic Risk in US Army Recruits and the Effects of Basic Combat Training. PLoS ONE 7(2): e31222. doi:10.1371/journal.pone.0031222

Editor: Conrad P. Earnest, Pennington Biomedical Research Center, United States of America

Received October 26, 2011; Accepted January 4, 2012; Published February 23, 2012

This is an open-access article, free of all copyright, and may be freely reproduced, distributed, transmitted, modified, built upon, or otherwise used by anyone for any lawful purpose. The work is made available under the Creative Commons CCO public domain dedication.

Funding: This work was funded by the United States Army Medical Research and Materiel Command. The funders had no role in study design, data collection and analysis, decision to publish, or preparation of the manuscript.

Competing Interests: The authors have declared that no competing interests exist.

* E-mail: james.mcclung@amedd.army.mil

These authors contributed equally to this work

\section{Introduction}

Cardiovascular and metabolic diseases remain leading causes of morbidity and mortality in the United States [1,2]. Smoking, sedentary lifestyle, and poor dietary habits have been established as modifiable behaviors contributing to the development and progression of cardiometabolic disease in part by promoting dyslipidemia, elevated blood glucose, and overweight/obesity [37]. Studies investigating primary and secondary cardiometabolic disease prevention strategies have traditionally focused on modifying health risk behaviors in older adults [8-11]. However, cardiometabolic diseases are progressive in nature, and early indications of disease are evident in adolescents and young adults [12-17] with some reports suggesting that more than a third of young adults entering college already exhibit one or more risk factors for cardiometabolic disease [18,19]. As exposure to cardiometabolic risk factors in childhood and adolescence is associated with disease development in adulthood [20-22] and health-risk behaviors are often established early in life, identifying strategies that deter the adoption and continuation of health risk behaviors in younger adults is essential for long-term primary prevention of cardiometabolic disease.

Military personnel are sometimes considered healthy, physically-fit adults that may be at low risk for developing cardiometabolic disease, as military service requires adherence to body composition, fitness [23], and medical standards [24]. However, evidence suggests that biomarkers and health-risk behaviors associated with cardiometabolic disease in military personnel may be similar to that observed in civilians $[25,26]$, with the rate of military personnel with a body mass index (BMI) exceeding $25 \mathrm{~kg} / \mathrm{m}^{2}$ at $62 \%$ and the prevalence of dyslipidemia [26] and smoking [27] at approximately $30 \%$. Further, as compared to historic data [25], military recruits are now less physically fit and heavier, with higher body fat, highlighting the necessity for effective primary prevention strategies.

Basic combat training (BCT) provides an opportunity for US Army Soldiers to adopt lifestyle behaviors that mitigate cardiometabolic disease risk. Lifestyle modifications include smoking and 
alcohol cessation, improved dietary habits through healthy food options at military dining facilities, and mandatory participation in standardized physical training. Whether the effects of militaryspecific physical training and behavioral modifications during BCT result in improvements in biomarkers of cardiometabolic disease risk in military recruits is undetermined. Therefore, this longitudinal study was conducted to characterize health-risk behaviors and cardiometabolic risk in US Army recruits at the start of BCT and to determine if lifestyle changes adopted during BCT influence biomarkers of disease risk. We hypothesized that cardiometabolic disease risk in US Army recruits would be consistent with that reported in college-aged adults and that completion of BCT would result in body fat loss, improved lipid profiles, and enhanced glycemic control.

\section{Materials and Methods}

\section{Subjects}

This study was approved by the Human Use Review Committee at the US Army Research Institute of Environmental Medicine and was conducted at Fort Jackson, SC. Human volunteers participated in the study after providing informed written voluntary consent. Investigators adhered to US Army Regulation 70-25 and US Army Medical Research and Material Command regulation 70-25 on the participation of volunteers in research.

US Army recruits who entered BCT during January 2010 volunteered to participate in this longitudinal trial. Anthropometrics, blood lipids, glucose, and insulin were assessed at baseline (wk 0) and again at wks 3, 6, and 9 of BCT. Demographics and health-risk behaviors (e.g., smoking and physical activity) associated with cardiometabolic risk were determined at wk 0 using health and family history questionnaires. A validated semiquantitative food frequency questionnaire was administered at wk 0 and wk 9 to assess habitual dietary intake and changes in dietary intake during training (Block 2005 FFQ; Nutrition Quest, Berkeley, CA) [28,29]. Non-plausible reporters, identified as men reporting an energy intake $>5000 \mathrm{kcal} / \mathrm{d}$ or $<800 \mathrm{kcal} / \mathrm{d}$ and women reporting energy intake $>4500 \mathrm{kcal} / \mathrm{d}$ or $<300 \mathrm{kcal} / \mathrm{d}$, were excluded from the analysis.

\section{Basic Combat Training}

US Army BCT is an integrated $10 \mathrm{wk}$ physical and didactic military training program. Physical training includes a combination of aerobic-type exercise activities such as road marching with weighted loads, obstacle courses, distance running, and sprinting, as well as muscular strength- and endurance-type training (e.g., push-ups, sit-ups, and pull-ups). Military-related activities such as rappelling, weapons training, hand-to-hand combative training, and didactic classroom instruction are also required during the course. Although not directly assessed in the present study, estimates of physical activity during BCT have been previously reported [30]. Soldiers reside in supervised barracks and alcohol and smoking abstention is mandatory during BCT.

Dietary intake is self-selected during BCT and limited to food and beverages offered in military dining facilities. Soldiers are given a choice of one entre, starch, and vegetable from a selection of meal options that cycle daily. In addition, Soldiers are also able to choose from a variety of desert items, fruits, and beverages at each meal. Standard military rations are provided during field training exercises. All meals, including rations, are designed to meet Military Dietary Reference Intakes [31], and provided in accordance with the Army Food Program [32].

\section{Anthropometrics and Body Composition}

Height was measured with a stadiometer (Creative Health Products, Plymouth, MI). Body mass was measured at each time point using a calibrated electronic scale (A\&A Scales, Prospect Park, NJ). BMI was calculated from measured height and body mass. Skinfold thickness was measured at wks 0 and 9 at the chest, triceps and subscapular sites for men, and at the triceps, suprailiac and abdominal sites for females with Lange calipers (Beta Technology, Santa Cruz, CA) to estimate body composition [33]. Body fat percentage was derived from body density calculated using 3-site skinfold equations [34-36]. Body composition measurements were performed under similar experimental conditions (fasted, similar attire) by the same trained technician.

\section{Biological Analyses}

Blood samples were collected after an overnight fast by antecubital venipuncture into tubes containing the appropriate anticoagulants (Vacutainer; Becton Dickson, Franklin Lakes, NJ). Serum was isolated, frozen, and shipped to the Pennington Biomedical Research Center (Baton Rouge, LA) for analysis of glucose, triglycerides (TG) and total (TC), low-density lipoprotein (LDL) and high-density lipoprotein (HDL) cholesterol using the Beckman Coulter DXG 600 Pro system (Beckman Coulter, Fullerton, CA). Insulin was assessed using an automated immunoassay instrument (Siemens Healthcare Diagnostics, Deerfield, IL); concentrations were used in the homeostasis model assessment of insulin resistance (HOMA-IR) [37].

\section{Statistical Analyses}

Dichotomous variables were created to identify the prevalence of US Army recruits exhibiting health-risk behaviors and the percentage of recruits with BMI, body fat and serum lipid levels indicative of increased cardiometabolic risk at wk 0 and wk 9. Sex differences for dichotomous variables were assessed using Fisher's Exact test. Difference in prevalence between wk 0 and wk 9 was assessed using McNemar's test. Student's t-tests were used to identify sex differences in anthropometric variables, and glucose and serum lipid concentrations at wk 0 . Two-factor (time and sex) mixed model repeated measures ANOVAs were used to examine changes in body mass, body fat percentage, glucose, HOMA-IR and serum lipid levels during BCT and to determine whether these changes differed by sex. Akaike's information criteria were used to determine appropriate covariance structures. Following observation of a significant sex-by-time interaction, post-hoc comparisons were completed using Bonferroni adjustments. Analyses were conducted using commercially available statistical software (SPSS 18.0; SPSS Inc., Chicago, IL). Descriptive statistics are presented as mean $\pm \mathrm{SD}$ unless otherwise noted. Significance was set at $P<0.05$

\section{Results}

\section{Volunteer characteristics}

Two hundred and nine US Army recruits [median age (yr) (interquartile range)], 118 males [21(19-25)], 91 females [21(1924)] participated in this trial. Average BMI at week 0 was higher $(P<0.05)$ for males $\left(27.0 \pm 4.3 \mathrm{~kg} / \mathrm{m}^{2}\right)$ compared to females $\left(25.0 \pm 2.9 \mathrm{~kg} / \mathrm{m}^{2}\right)$; however, percent body fat was lower $(P<0.05)$ in males $(14.2 \pm 4.6 \%)$ versus females $(26.7 \pm 5.8 \%)$. Percent body fat for Soldiers with a BMI less than $30 \mathrm{~kg} / \mathrm{m}^{2}$ was $13.0 \pm 3.9 \%$ in males and $26.3 \pm 5.5 \%$ in females. When BMI exceeded $30 \mathrm{~kg} / \mathrm{m}^{2}$, percent body fat was $18.8 \pm 4.4 \%$ in males and $36.6 \pm 3.3 \%$ in females. In all cases, percent body fat was lower $(P<0.05)$ in males. Volunteers $(n)$ identified themselves as either 
white or Caucasian (72 males, 55 females), black or African American (19 males, 24 females), Asian (5 males, 1 female), or other (22 males, 11 females).

\section{Macronutrient distribution of the diet at the start and completion of basic combat training}

The percentage of total energy obtained from carbohydrate $(48.8 \pm 8.3 \%)$, protein $(15.7 \pm 3.6 \%)$, and fat $(35.2 \pm 6.7 \%)$ was similar between males and females prior to BCT. At the completion of BCT, energy obtained from carbohydrate increased (main effect of time, $P<0.05$ ) in both males (wk 0: $48.5 \pm 8 \%$ vs. wk 9: $51.9 \pm 6.8 \%$ ) and females (wk 0: $49.1 \pm 8.7 \%$ vs. wk 9: $53.9 \pm 6.2 \%)$. Compared to wk 0 , total energy derived from protein remained steady at wk 9 , with no differences between men and women. Total energy derived from fat remained stable in males but decreased (sex-by-time interaction, $P<0.05$ ) in females at wk $9(33.0 \pm 5.3 \%)$ as compared to wk $0(35.4 \pm 7 \%)$.

\section{Cardiometabolic risk at the start of basic combat training}

Cardiometabolic risk was evident in new recruits at the beginning of BCT (Table 1). Nearly one third of recruits reported smoking or engaging in $<20 \mathrm{~min} / \mathrm{d}$ of physical activity prior to BCT, and a third reported a family history of cardiometabolic disease. Fourteen percent of all Soldiers had a BMI in excess of $30 \mathrm{~kg} / \mathrm{m}^{2}$. However, the prevalence of recruits with a BMI above $30 \mathrm{~kg} / \mathrm{m}^{2}$ was five times higher $(P<0.05)$ in males. More than half of all recruits were not meeting recommendations for total or saturated fat, fiber, or fruit and vegetable intakes, with no differences between men and women. Mean TC $(156 \pm 29 \mathrm{mg} / \mathrm{dL})$, LDL $(93 \pm 25 \mathrm{mg} / \mathrm{dL})$, HDL (males: $45 \pm 11 \mathrm{mg} / \mathrm{dL}$, females: $54 \pm 11 \mathrm{mg} / \mathrm{dL}), \mathrm{TG}(69 \pm 35 \mathrm{mg} / \mathrm{dL})$, and glucose $(88 \pm 8 \mathrm{mg} / \mathrm{dL})$ were within recommended ranges at wk 0 . Females had higher HDL, and lower TG (males: $76 \pm 39 \mathrm{mg} / \mathrm{dL}$, females: $60 \pm 28 \mathrm{mg} / \mathrm{dL}$ ) and glucose (males: $90 \pm 7 \mathrm{mg} / \mathrm{dL}$, females: $85 \pm 8 \mathrm{mg} / \mathrm{dL})$ concentrations compared to males $(P<0.05)$. However, TC was above recommended levels in $8 \%$, LDL in $39 \%$, TG in $5 \%$, and glucose in $8 \%$ of recruits, and HDL was below recommended levels in 33\% of recruits. In the cohort of recruits not meeting blood glucose or lipid recommendations, mean TC, LDL, TG, HDL and glucose concentrations were $215 \pm 19 \mathrm{mg} / \mathrm{dL}$, $118 \pm 17 \mathrm{mg} / \mathrm{dL}, 186 \pm 24 \mathrm{mg} / \mathrm{dL}, 37 \pm 6 \mathrm{mg} / \mathrm{dL}$ and $103 \pm 4 \mathrm{mg} /$ dL, respectively.

\section{Cardiometabolic risk at the completion of basic combat training}

The prevalence of recruits with risk factors associated with increased cardiometabolic risk was decreased at wk 9 as compared to baseline (Table 1). Energy obtained from saturated fat decreased $(P<0.05)$ while fiber, fruit, and vegetable intake increased during BCT (main effect of time, $P<0.05$ ). As such, more than half of recruits met recommendations for total fat, saturated fat, or fruit and vegetable intake by the end of BCT. Compared to wk 0 , fewer $(P<0.05)$ recruits were obese, and fewer $(P<0.05)$ had LDL or glucose concentrations that exceeded recommended levels. The prevalence of recruits with elevated TC $(8 \%$ vs. $3 \%)$ and TG (5\% vs. $2 \%)$ concentrations also declined, though the difference did not reach statistical significance. The prevalence of recruits with HDL levels below recommended levels increased (33\% vs. $39 \%$ ) but did not reach statistical significance.

\section{Effects of basic combat training on anthropometrics and biomarkers of cardiometabolic risk}

Body mass remained stable in women but decreased in men during BCT (sex-by-time interaction, $P<0.05$; Table 2). Overall,
Table 1. Percentage of US Army recruits demonstrating health-risk behaviors and having blood glucose or lipid levels indicative of increased cardiometabolic risk before and after basic combat training.

\begin{tabular}{|c|c|c|c|c|c|}
\hline \multirow[b]{3}{*}{ Risk factor } & \multirow[b]{3}{*}{ Health-risk } & \multirow[b]{2}{*}{ Week } & \multicolumn{3}{|c|}{$\begin{array}{l}\text { Demonstrating health } \\
\text { risk (\%) }\end{array}$} \\
\hline & & & Male & Female & Total \\
\hline & & $(0-9)$ & $\begin{array}{l}(n=84- \\
118)\end{array}$ & $(n=67-91)$ & \\
\hline $\begin{array}{l}\text { Family } \\
\text { history }^{1}\end{array}$ & $\begin{array}{l}\text { Ml, stroke, } \\
\text { or diabetes }\end{array}$ & & 35 & 32 & 34 \\
\hline \multicolumn{6}{|c|}{ Health risk behaviors } \\
\hline Smoker & $\geq 1$ cigarette/d & & 24 & 31 & 27 \\
\hline Sedentary & $<20$ min activity/d & & 32 & 43 & 37 \\
\hline \multicolumn{6}{|c|}{ Anthropometric indicators } \\
\hline BMI & $>30 \mathrm{~kg} / \mathrm{m}^{2}$ & 0 & 22 & $4^{a}$ & 14 \\
\hline Biomarker $^{2,3}$ & & 9 & $12^{\mathrm{b}}$ & $0^{\mathrm{a}}$ & $7^{b}$ \\
\hline \multirow[t]{2}{*}{ Glucose } & $\geq 100 \mathrm{mg} / \mathrm{dL}$ & 0 & 11 & 4 & 8 \\
\hline & & 9 & 5 & $0^{\mathrm{b}}$ & $3^{\mathrm{b}}$ \\
\hline \multirow[t]{2}{*}{ TC } & $\geq 200 \mathrm{mg} / \mathrm{dL}$ & 0 & 8 & 9 & 8 \\
\hline & & 9 & 3 & 3 & 3 \\
\hline \multirow[t]{4}{*}{ LDL } & $\geq 100 \mathrm{mg} / \mathrm{dL}$ & 0 & 44 & 31 & 39 \\
\hline & & 9 & $20^{\mathrm{b}}$ & 21 & $21^{\mathrm{b}}$ \\
\hline & $\geq 130 \mathrm{mg} / \mathrm{dL}$ & 0 & 6 & 10 & 8 \\
\hline & & 9 & 3 & $1^{\mathrm{b}}$ & $2^{\mathrm{b}}$ \\
\hline \multirow[t]{2}{*}{ HDL } & $\mathrm{M}: \leq 40 \mathrm{mg} / \mathrm{dL}$ & 0 & 29 & 38 & 33 \\
\hline & $\mathrm{F}: \leq 50 \mathrm{mg} / \mathrm{dL}$ & 9 & 31 & $49^{a}$ & 39 \\
\hline \multirow[t]{2}{*}{ TG } & $\geq 150 \mathrm{mg} / \mathrm{dL}$ & 0 & 6 & 3 & 5 \\
\hline & & 9 & 1 & 4 & 2 \\
\hline \multicolumn{6}{|l|}{ Dietary intake 4} \\
\hline \multirow[t]{2}{*}{ Total fat } & $\geq 35 \%$ total $\mathrm{kcal}$ & 0 & 50 & 51 & 50 \\
\hline & & 9 & 42 & $33^{\mathrm{b}}$ & $38^{\mathrm{b}}$ \\
\hline \multirow[t]{2}{*}{ Saturated fat } & $\geq 10 \%$ total $\mathrm{kcal}$ & 0 & 63 & 63 & 63 \\
\hline & & 9 & 51 & $40^{b}$ & $46^{b}$ \\
\hline \multirow[t]{2}{*}{ Cholesterol } & $\geq 300$ mg/day & 0 & 43 & 36 & 40 \\
\hline & & 9 & 70 & $54^{a, b}$ & $63^{b}$ \\
\hline \multirow[t]{2}{*}{ Sodium $^{5}$} & $\geq 2300 \mathrm{mg} / \mathrm{d}$ & 0 & 74 & $49^{a}$ & 63 \\
\hline & & 9 & $89^{b}$ & $72^{a, b}$ & $82^{\mathrm{b}}$ \\
\hline \multirow[t]{2}{*}{ Fiber } & $<28 \mathrm{~g} / \mathrm{d}$ & 0 & 93 & 88 & 91 \\
\hline & & 9 & $82^{\mathrm{b}}$ & 90 & 85 \\
\hline Fruits and & $<5$ servings/d & 0 & 79 & 78 & 78 \\
\hline Vegetables & & 9 & $49^{b}$ & $48^{\mathrm{b}}$ & $48^{\mathrm{b}}$ \\
\hline
\end{tabular}

TC, total cholesterol; LDL, low-density lipoprotein cholesterol; HDL, high-density lipoprotein cholesterol; TG, triglycerides.

${ }^{1}$ Myocardial infarction (MI), stroke, cardiovascular operation or diabetes reported in mother or father.

${ }^{2}$ National Cholesterol Education Program (NCEP) Expert Panel on Detection,

Evaluation, and Treatment of High Blood Cholesterol in Adults (Adult

Treatment Panel III) [49].

${ }^{3}$ Diagnosis and Management of the Metabolic Syndrome: An American Heart Association/National Heart, Lung, and Blood Institute Scientific Statement [50]. ${ }^{4}$ Dietary Guidelines for Americans, 2010 [51].

${ }^{5}$ Nutrition for Athletic Performance Joint Position Stand [52]

${ }^{\mathrm{a}}$ Fisher's Exact test; different from males, $P<0.05$.

${ }^{\mathrm{b}}$ McNemar's test; different from week $0, P<0.05$.

doi:10.1371/journal.pone.0031222.t001 
Table 2. Body mass and body composition of US Army recruits during basic combat training. ${ }^{1}$

\begin{tabular}{|c|c|c|c|c|c|c|}
\hline & Week 0 & & Week 3 & Week 6 & Week 9 & \\
\hline \multicolumn{7}{|l|}{ Body mass $(\mathrm{kg})^{2}$} \\
\hline Male & $84.0 \pm 16.2$ & & $82.3 \pm 14.4^{a}$ & $81.5 \pm 13.0^{a, b}$ & $80.3 \pm 12.4^{\mathrm{a}, \mathrm{b}, \mathrm{c}}$ & \\
\hline Female & $66.3 \pm 8.3$ & & $66.2 \pm 7.8$ & $66.8 \pm 7.6^{b}$ & $66.4 \pm 7.4$ & \\
\hline \multicolumn{7}{|l|}{ Body fat $(\%)^{2}$} \\
\hline Male & $14.3 \pm 4.8$ & & - & - & $12.3 \pm 3.5^{\mathrm{a}}$ & \\
\hline Female & $26.6 \pm 5.6$ & & - & - & $22.8 \pm 5.1^{\mathrm{a}}$ & \\
\hline \multicolumn{7}{|l|}{ Fat-free mass $(\mathrm{kg})^{2}$} \\
\hline Male & $71.7 \pm 11.4$ & & - & - & $70.3 \pm 9.4^{\mathrm{a}}$ & \\
\hline Female & $48.2 \pm 4.8$ & & - & - & $51.0 \pm 5.3^{\mathrm{a}}$ & \\
\hline Body fat (\%) by $B M I^{2}$ & $<30 \mathrm{~kg} / \mathrm{m}^{2}$ & $\geq 30 \mathrm{~kg} / \mathrm{m}^{2}$ & & & $<30 \mathrm{~kg} / \mathrm{m}^{2}$ & $\geq 30 \mathrm{~kg} / \mathrm{m}^{2}$ \\
\hline Male & $12.9 \pm 4.0$ & $18.4 \pm 4.4^{d}$ & - & - & $11.7 \pm 2.8$ & $16.9 \pm 4.1^{\mathrm{a}, \mathrm{d}}$ \\
\hline Female & $26.3 \pm 5.4$ & $35.9 \pm 3.9^{d}$ & - & - & $22.9 \pm 5.0$ & $\mathrm{n}=0^{\mathrm{a}}$ \\
\hline
\end{tabular}

${ }^{1}$ Mean $\pm \mathrm{SD} ; \mathrm{n}=100 \mathrm{M}, 71 \mathrm{~F}$.

${ }^{2}$ Two-factor mixed model repeated measures ANOVA with Bonferroni corrections. Sex-by-time interaction $(P<0.05)$. Different from

aweek 0,

b week 3,

cweek 6,

$\mathrm{d}_{<}<30 \mathrm{~kg} / / \mathrm{m}^{2} \mathrm{p}<0.05$

doi:10.1371/journal.pone.0031222.t002

percent body fat was lower $(P<0.05)$ and fat-free mass $(\mathrm{FFM})$ was higher $(P<0.05)$ in males compared to females. Percent body fat decreased in both men and women (sex-by-time interaction, $P<0.05$ ), however, females gained FFM during BCT, whereas males lost FFM from wk 0 to wk 9 (sex-by-time interaction, $P<0.05)$.

Sex differences in the responses of TC, LDL, HDL and TG levels to BCT (sex-by-time interaction, $P<0.05$ ) were observed (Figure 1). In men, TC, LDL and TG concentrations decreased $(P<0.05)$ by wk 3 . Compared to wk 0 , TC, LDL and TG concentrations at wk 9 were $8 \%, 10 \%$ and $13 \%$ lower $(P<0.05)$, respectively. In women, TC and LDL concentrations were below $(P<0.05)$ wk 0 values at wk 3 and wk 6 , but were not different from wk 0 at wk 9. Triglycerides increased $(P<0.05) 19 \%$ during BCT in women. Although a modest reduction in HDL was observed in men at wk 6, wk 9 HDL concentrations were not different from wk 0 . HDL concentrations remained stable in women.

Plasma insulin levels remained stable in women but decreased in men during BCT (sex-by-time interaction, $P<0.05$; Table 3). Sex differences in the responses of glucose, and HOMA-IR values (sex-by-time interaction, $P<0.05$ ) were also observed (Figure 2). Glucose concentrations decreased $(P<0.05)$ by wk 3 in both men and women. At wk 9, glucose concentrations were $6 \%$ lower $(P<0.05)$ than at wk 0 in men, but not different from wk 0 in women. In men, HOMA-IR decreased $(P<0.05)$ by wk 3 and stabilized before increasing from wk 6 to wk 9. In women, HOMA-IR was below wk 0 values at wk 6 , but was not different from wk 0 at wk 9.

\section{Discussion}

As lifestyle behaviors adopted early in life may increase the risk of developing cardiometabolic disease in adulthood, risk factor identification and management in young adults should be a primary focus of long-term disease prevention. To the best of our knowledge, this is the first evaluation of behavioral, demographic, and biochemical indicators of cardiometabolic risk in US Army recruits and the effects of military training on cardiometabolic

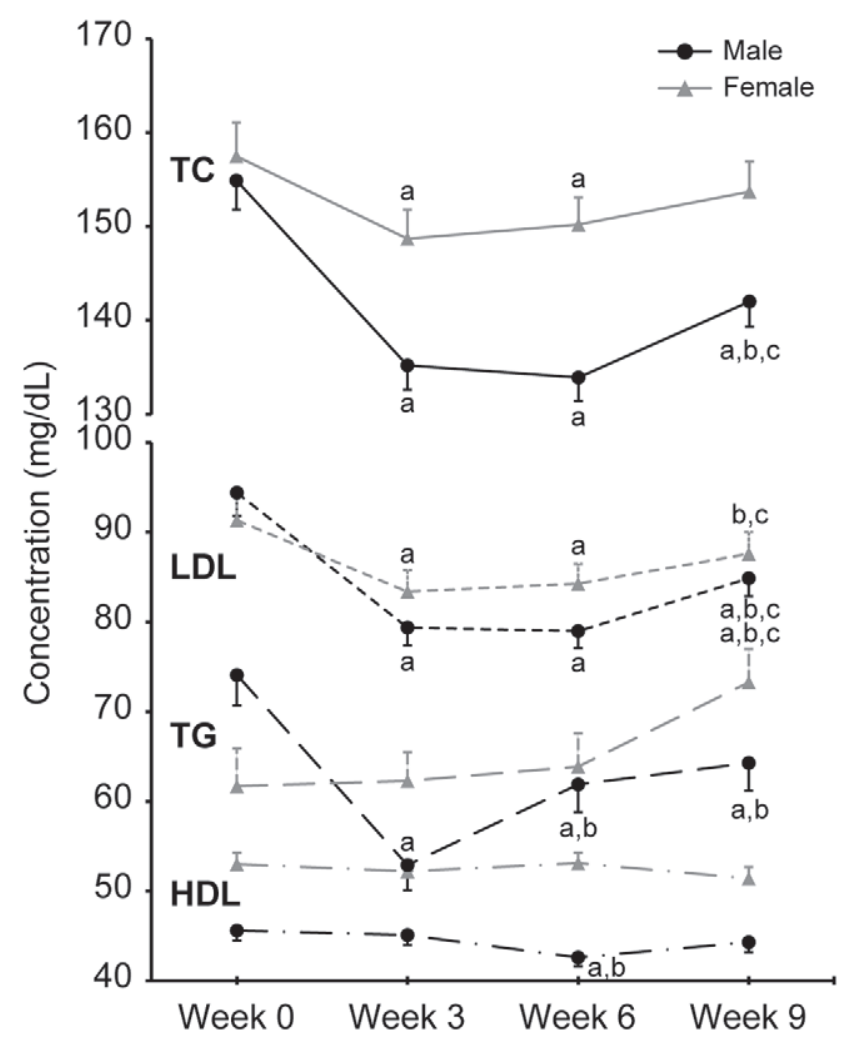

Figure 1. Effect of basic combat training on blood lipids and triglycerides. All values are mean \pm SEM; $n=100 M, 71 F ; T C$, total cholesterol; LDL, low-density lipoprotein cholesterol; HDL, high-density lipoprotein cholesterol; TG, triglycerides. Two-factor mixed model repeated measures ANOVA. Sex-by-time interaction observed for all biomarkers, $P<0.05$. Different from ${ }^{\mathrm{a}}$ week 0 , ${ }^{\mathrm{b}}$ week 3 , ${ }^{\mathrm{c}}$ week $6, P<0.05$. doi:10.1371/journal.pone.0031222.g001 
Table 3. Insulin levels of US Army recruits during basic combat training. ${ }^{1}$

\begin{tabular}{lcccc}
\hline & Week 0 & Week 3 & Week 6 & Week 9 \\
\hline Insulin $(\mu / U / \mathrm{mL})^{2}$ & & & & \\
Male $^{2}$ & $5.9 \pm 0.4$ & $2.9 \pm 0.4^{\mathrm{a}}$ & $3.5 \pm 0.3^{\mathrm{a}}$ & $3.8 \pm 0.4^{\mathrm{a}}$ \\
Female & $5.1 \pm 0.5$ & $5.3 \pm 0.5^{\mathrm{b}}$ & $4.2 \pm 0.4$ & $5.1 \pm 0.4^{\mathrm{b}}$ \\
\hline
\end{tabular}

${ }^{1}$ Mean \pm SD; $\mathrm{n}=100 \mathrm{M}, 71 \mathrm{~F}$.

${ }^{2}$ Two-factor mixed model repeated measures ANOVA with Bonferroni

corrections. Sex-by-time interaction $(P<0.05)$. Different from

aweek 0 ,

${ }^{\mathrm{b}}$ males, $P<0.05$.

doi:10.1371/journal.pone.0031222.t003

disease risk factors. Similar to the corresponding civilian demographic, health-risk behaviors and cardiometabolic risk factors were evident in US Army recruits before starting BCT. Most importantly, indicators of cardiometabolic disease risk were diminished after participating in standardized military training, as evidenced by improved lipid profiles, enhanced glycemic regulation, and favorable changes in body composition. These findings emphasize the benefits of standardized military training for reducing common risk factors associated with the development and progression of cardiometabolic disease.

Our laboratory has an established record of documenting the effects of military training on nutritional status indicators of health and performance $[38,39]$. However, the current investigation was novel as studies rarely track cardiometabolic risk over time in similar civilian demographics, whereas our study provides a longitudinal evaluation in young adults before, during, and after engaging in a comprehensive training program. We recognize that the collection of data at only one military location, lack of assessments of physical activity, as well as the use of foodfrequency questionnaires could be considered limitations that may affect the extension and interpretation of study outcomes. Certainly, characterizing additional subsets of recruits beginning BCT at other training sites would have provided a more representative cross-sectional analysis of cardiometabolic risk and the effects of military training in US Army recruits. Nevertheless,

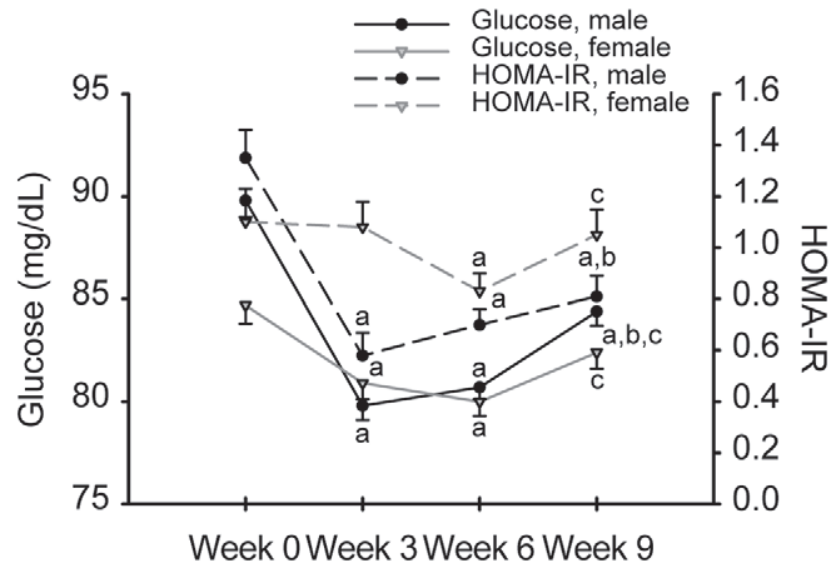

Figure 2. Effect of basic combat training on blood glucose and HOMA-IR. All values are mean \pm SEM; $n=100 \mathrm{M}, 71 \mathrm{~F}$. Two-factor mixed model repeated measures ANOVA. Sex-by-time interaction observed for all biomarkers, $P<0.05$. Different from ${ }^{\mathrm{a}}$ week $0,{ }^{\mathrm{b}}$ week 3 , cweek 6, $P<0.05$.

doi:10.1371/journal.pone.0031222.g002 for the first time, the current study determined cardiometabolic risk in new recruits entering military service, which was reduced during structured military training.

The prevalence of recruits reporting health-risk behaviors such as smoking, physical inactivity and poor dietary habits was generally comparable with or slightly greater than findings reported within similar civilian demographics. For example, the prevalence of smoking in recruits $(27 \%)$ was similar to the prevalence reported in young adults responding to the 2003 Behavioral Risk Factor Surveillance System (29\%, BRFSS) [14], and the prevalence of recruits reporting physical inactivity $(37 \%)$ was similar to the $41 \%$ reported in the BRFSS [14]. The percentage of recruits who were obese $(14 \%)$ was much lower than US population estimates (34\%) for adults 20-39 yr [40]. Although obesity rates appear different in recruits, it is important to recognize that new recruits must meet body weight standards in order to enter military service. We also observed LDL concentrations above recommendations and suboptimal HDL in a third of new recruits at the start of BCT. Recent data from Burke et al. [18] and the Tufts University Longitudinal Health Study (TLHS) [19] suggest that the prevalence of lipid abnormalities observed in military recruits was similar to dyslipidemia rates reported in college populations. Moreover, mean TC, LDL and glucose concentrations were not only similar to that reported in the TLHS [19] but lower than those reported in the general US population of adults age 20-29 yr [41]. Taken together these findings indicate that cardiometabolic risk in US Army recruits may be somewhat lower than that of the general civilian population and more comparable to the risk status of college students.

The favorable changes observed in biochemical indicators associated with cardiometabolic risk are likely due in large part to the comprehensive lifestyle modifications required during BCT. These modifications include structured, frequent physical training, and mandatory smoking and alcohol abstention. Physical training has generally been associated with increased HDL concentrations and reduced LDL and TG concentrations [42-44]. Specifically, training that elicits an energy expenditure of $1200-2200 \mathrm{kcal} / \mathrm{wk}$ has been shown to increase HDL concentrations by $2-8 \mathrm{mg} / \mathrm{dL}$ and reduce TG levels by $5-38 \mathrm{mg} / \mathrm{dL}$ [45]. Others suggest that the intensity, volume and type (e.g., aerobic, resistance, or combined aerobic and resistance exercise) of physical activity dictates blood lipid responses to training [42-44]. In this case, military training incorporates aerobic and resistance training activities across all levels of exercise intensity. Further, the training volume is high, as recent evidence suggests that Soldiers travel approximately 7.5 miles/d during BCT [30]. We suspect that the high levels of energy expenditure associated with the volume of physical activity during BCT and the variety of exercise modalities performed may be the underlying cause for the dynamic decreases in TC, LDL and TG observed within the first $3 \mathrm{wk}$ of training. Although physical activity during BCT may have contributed in large part to the reduction in blood lipids, the overall intensity and volume, which is not prescribed or adjusted based on Soldiers' sex or body mass, may still have been insufficient to elicit an increase in HDL. Nevertheless, the blood lipid and glycemic response is associated with reduced cardiometabolic risk, and interestingly, was more robust in male Soldiers. These findings are at odds with a review from Leon et al. [43], who concluded that the blood lipid responses to physical training occur independent of sex. As such, the sex differences observed in this trial may be related to the higher glucose and TG, and lower HDL observed in male Soldiers at baseline or the absence of weight loss in female Soldiers.

Although the risk of developing cardiometabolic disease in US Army recruits is generally low, the importance of establishing 
healthy behaviors that affect body weight, body composition, blood lipids, and indicators of glycemic control cannot be understated. Previous studies have established that cardiometabolic disease progression begins early in life [12,13,20,46] and demonstrate the cumulative effects of dyslipidemia through childhood and young adulthood on disease risk in adults $[21,22,47]$. In this study, elevated lipid levels for Soldiers that failed to meet recommendations might be considered biologically insignificant; however, establishing healthy lipid levels early in life may be associated with delayed atherosclerosis and a reduced incidence of cardiometabolic events [48]. As such, our findings, which demonstrate that the lifestyle modifications required during military training favorably influence biomarkers associated with cardiometabolic risk, are clinically significant. Accordingly, military training may mitigate or reverse disease progression if the habits formed during such training are sustained. However, future study is required to determine if Soldiers adopt and maintain the healthy behaviors encouraged during BCT throughout their military careers. Recent reports indicate that Soldiers are making beneficial lifestyle changes after training, yet the number who smoke, are overweight, or maintain suboptimal physical activity and diet regimens remains concerning [27].

In summary, this study demonstrated that the prevalence of health-risk behaviors and biomarkers associated with increased cardiometabolic risk in US Army recruits is similar to that reported in college-age populations at the start of training. More importantly, our findings document the importance of adopting healthy lifestyle modifications for mitigating cardiometabolic risk through improved blood lipids, body composition, and glycemic

\section{References}

1. Heron M, Hoyert DL, Murphy SL, Xu J, Kochanek KD, et al. (2009) Deaths: final data for 2006. Natl Vital Stat Rep 57: 1-134.

2. Keenan NL, Shaw KM (2011) Coronary heart disease and stroke deaths United States, 2006. MMWR Surveill Summ 60 Suppl: 62-66.

3. Carroll MD, Lacher DA, Wolz M, Sorlie PD (2011) 30-year trends in serum lipids among United States adults: results from the national health and nutrition examination surveys II, III, and 1999-2006. Am J Cardiol 107: 1868-1870.

4. Li C, Ford ES, Tsai J, Zhao G, Balluz LS, et al. (2011) Serum non-high-density lipoprotein cholesterol concentration and risk of death from cardiovascular diseases among U.S. adults with diagnosed diabetes: the Third National Health and Nutrition Examination Survey linked mortality study. Cardiovasc Diabetol 10: 46 .

5. Luke A, Dugas LR, Durazo-Arvizu RA, Cao G, Cooper RS (2011) Assessing physical activity and its relationship to cardiovascular risk factors: NHANES 2003-2006. BMC Public Health 11: 387.

6. Zhao G, Ford ES, Li C, Tsai J, Dhingra S, et al. (2011) Waist Circumference, Abdominal Obesity, and Depression among Overweight and Obese U.S. Adults: National Health and Nutrition Examination Survey 2005-2006. BMC Psychiatry 11: 130

7. Zhao G, Ford ES, Li C, Balluz LS (2011) Physical activity in U.S. older adults with diabetes mellitus: prevalence and correlates of meeting physical activity recommendations. J Am Geriatr Soc 59: 132-137.

8. Dugas LR, Gao G, Luke AH, Durazo-Arvizu RA (2011) Adiposity Is Not Equal in a Multi-Race/Ethnic Adolescent Population: NHANES 1999-2004. Obesity (Silver Spring) 10: 2099-101.

9. Harris JR, Huang Y, Hannon PA, Williams B (2011) Low-socioeconomic status workers: their health risks and how to reach them. J Occup Environ Med 53: 132-138.

10. Liao Y, Bang D, Cosgrove S, Dulin R, Harris Z, et al. (2011) Surveillance of health status in minority communities - Racial and Ethnic Approaches to Community Health Across the U.S. (REACH U.S.) Risk Factor Survey, United States, 2009. MMWR Surveill Summ 60: 1-44.

11. Paeratakul S, Lovejoy JC, Ryan DH, Bray GA (2002) The relation of gender, race and socioeconomic status to obesity and obesity comorbidities in a sample of US adults. Int J Obes Relat Metab Disord 26: 1205-1210.

12. McGill HC, Jr., McMahan CA, Zieske AW, Tracy RE, Malcom GT, et al. (2000) Association of Coronary Heart Disease Risk Factors with microscopic qualities of coronary atherosclerosis in youth. Circulation 102: 374-379.

13. McMahan CA, Gidding SS, Fayad ZA, Zieske AW, Malcom GT, et al. (2005) Risk scores predict atherosclerotic lesions in young people. Arch Intern Med 165: $883-890$ regulation. Studies to determine if modifications implemented during military training, including structured physical training and improved dietary habits, result in long-term lifestyle adaptations and protection against the development of cardiometabolic disease in active duty military personnel and military veterans are required. Our findings suggest that meaningful changes in cardiometabolic risk profiles in young adults can be achieved in a short period time by consuming a healthy diet and participating in regular physical activity.

\section{Acknowledgments}

We acknowledge the Soldier volunteers that participated in this study and the command staff at Fort Jackson, SC, who provided access to potential volunteers. We thank Philip Niro, Lauren Thompson, Ellen Glickman, Michael Stanger, Bryan Wiley, Matthew Dickson, Jay O'Hara, Ryan Regalia, Nate Hendrickson, Leila Walker, and the technical staff at the Pennington Biomedical Research Center for their significant contributions to the experiments detailed within this manuscript. The opinions or assertions contained herein are the private views of the authors and are not to be construed as official or as reflecting the views of the Army or the Department of Defense. Any citations of commercial organizations and trade names in this report do not constitute an official Department of the Army endorsement or approval of the products or services of these organizations.

\section{Author Contributions}

Conceived and designed the experiments: JPK SJC KWW AJY JPM. Performed the experiments: SMP JPK LJL NEM LMM JCR SJC KWW JPM. Analyzed the data: JPK LJL SMP. Wrote the paper: SMP JPK JPM.

14. McCracken M, Jiles R, Blanck HM (2007) Health behaviors of the young adult U.S. population: behavioral risk factor surveillance system, 2003. Prev Chronic Dis 4: A25.

15. Kuklina EV, Yoon PW, Keenan NL (2010) Prevalence of coronary heart disease risk factors and screening for high cholesterol levels among young adults, United States, 1999-2006. Ann Fam Med 8: 327-333.

16. Okosun IS, Boltri JM, Lyn R, vis-Smith M (2010) Continuous metabolic syndrome risk score, body mass index percentile, and leisure time physical activity in American children. J Clin Hypertens (Greenwich) 12: 636-644.

17. Tirosh A, Shai I, Afek A, Dubnov-Raz G, Ayalon N, et al. (2011) Adolescent BMI trajectory and risk of diabetes versus coronary disease. N Engl J Med 364: 1315-1325.

18. Burke JD, Reilly RA, Morrell JS, Lofgren IE (2009) The University of New Hampshire's Young Adult Health Risk Screening Initiative. J Am Diet Assoc 109: 1751-1758.

19. Sacheck JM, Kuder JF, Economos CD (2010) Physical fitness, adiposity, and metabolic risk factors in young college students. Med Sci Sports Exerc 42: 1039-1044.

20. Mahoney LT, Burns TL, Stanford W, Thompson BH, Witt JD, et al. (1996) Coronary risk factors measured in childhood and young adult life are associated with coronary artery calcification in young adults: the Muscatine Study. J Am Coll Cardiol 27: 277-284.

21. Raitakari OT, Juonala M, Kahonen M, Taittonen L, Laitinen T, et al. (2003) Cardiovascular risk factors in childhood and carotid artery intima-media thickness in adulthood: the Cardiovascular Risk in Young Finns Study. JAMA 290: 2277-2283.

22. Srinivasan SR, Frontini MG, Xu J, Berenson GS (2006) Utility of childhood non-high-density lipoprotein cholesterol levels in predicting adult dyslipidemia and other cardiovascular risks: the Bogalusa Heart Study. Pediatrics 118: 201-206.

23. Department of the Army (2006) The Army Weight Control Program. AR 600-9.

24. Department of the Army (2007) Standards of Medical Fitness. AR 40-501.

25. Knapik JJ, Sharp MA, Darakjy S, Jones SB, Hauret KG, et al. (2006) Temporal changes in the physical fitness of US Army recruits. Sports Med 36: 613634.

26. McGraw LK, Turner BS, Stotts NA, Dracup KA (2008) A review of cardiovascular risk factors in US military personnel. J Cardiovasc Nurs 23: 338-344.

27. Bray RM, Pemberton MR, Hourani LL, Witt M, Rae Olmsted KL, et al. (2009) 2008 Department of Defense Survey of Health Related Behaviors Among Active Duty Military Personnel. 
28. Block G, Hartman AM, Dresser CM, Carroll MD, Gannon J, et al. (1986) A data-based approach to diet questionnaire design and testing. Am J Epidemiol 124: 453-469.

29. Block G, Woods M, Potosky A, Clifford C (1990) Validation of a selfadministered diet history questionnaire using multiple diet records. J Clin Epidemiol 43: 1327-1335.

30. KnapikJJ, Darakjy S, Hauret KG, Canada S, Marin R, et al. (2007) Ambulatory physical activity during United States Army basic combat training. Int J Sports Med 28: 106-115.

31. Department of the Army (2001) Nutrition Standards and Education. AR 40-25.

32. Department of the Army (2005) The Army Food Program. AR 30-22.

33. Whaley MH, Brubaker PH, Otto RM, eds (2006) Health-related physical fitness testing and interpretation. In: ACSM's Guidelines for Exercise Testing and Prescription. Baltimore: Lippincott Williams \& Wilkins. pp 55-92.

34. Heyward VH (1996) Evaluation of body composition. Current issues. Sports Med 22: 146-156.

35. Jackson AS, Pollock ML (1978) Generalized equations for predicting body density of men. Br J Nutr 40: 497-504.

36. Jackson AS, Pollock ML, Ward A (1980) Generalized equations for predicting body density of women. Med Sci Sports Exerc 12: 175-181.

37. Matthews DR, Hosker JP, Rudenski AS, Naylor BA, Treacher DF, et al. (1985) Homeostasis model assessment: insulin resistance and beta-cell function from fasting plasma glucose and insulin concentrations in man. Diabetologia 28: 412-419.

38. Karl JP, Lieberman HR, Cable SJ, Williams KW, Young AJ, et al. (2010) Randomized, double-blind, placebo-controlled trial of an iron-fortified food product in female soldiers during military training: relations between iron status, serum hepcidin, and inflammation. Am J Clin Nutr 92: 93-100.

39. McClung JP, Karl JP, Cable SJ, Williams KW, Nindl BC, et al. (2009) Randomized, double-blind, placebo-controlled trial of iron supplementation in female soldiers during military training: effects on iron status, physical performance, and mood. Am J Clin Nutr 90: 124-131.

40. Flegal KM, Carroll MD, Ogden CL, Curtin LR (2010) Prevalence and trends in obesity among US adults, 1999-2008. JAMA 303: 235-241.

41. Carroll MD, Lacher DA, Sorlie PD, Cleeman JI, Gordon DJ, et al. (2005) Trends in serum lipids and lipoproteins of adults, 1960-2002. JAMA 294: 1773-1781.
42. Halbert JA, Silagy CA, Finucane P, Withers RT, Hamdorf PA (1999) Exercise training and blood lipids in hyperlipidemic and normolipidemic adults: a metaanalysis of randomized, controlled trials. Eur J Clin Nutr 53: 514-522.

43. Leon AS, Sanchez OA (2001) Response of blood lipids to exercise training alone or combined with dietary intervention. Med Sci Sports Exerc 33: S502-S515.

44. Tambalis K, Panagiotakos DB, Kavouras SA, Sidossis LS (2009) Responses of blood lipids to aerobic, resistance, and combined aerobic with resistance exercise training: a systematic review of current evidence. Angiology 60: 614-632.

45. Durstine JL, Grandjean PW, Davis PG, Ferguson MA, Alderson NL, et al. (2001) Blood lipid and lipoprotein adaptations to exercise: a quantitative analysis. Sports Med 31: 1033-1062.

46. Oren A, Vos LE, Uiterwaal CS, Grobbee DE, Bots ML (2003) Cardiovascular risk factors and increased carotid intima-media thickness in healthy young adults: the Atherosclerosis Risk in Young Adults (ARYA) Study. Arch Intern Med 163: 1787-1792.

47. Davis PH, Dawson JD, Riley WA, Lauer RM (2001) Carotid intimal-medial thickness is related to cardiovascular risk factors measured from childhood through middle age: The Muscatine Study. Circulation 104: 2815-2819.

48. Steinberg D (2006) Thematic review series: the pathogenesis of atherosclerosis. An interpretive history of the cholesterol controversy, part V: the discovery of the statins and the end of the controversy. J Lipid Res 47: 1339-1351.

49. (2002) Third Report of the National Cholesterol Education Program (NCEP) Expert Panel on Detection, Evaluation, and Treatment of High Blood Cholesterol in Adults (Adult Treatment Panel III) final report. Circulation 106: 3143-3421.

50. Grundy SM, Cleeman JI, Daniels SR, Donato KA, Eckel RH, et al. (2006) Diagnosis and management of the metabolic syndrome: an American Heart Association/National Heart, Lung, and Blood Institute scientific statement. Curr Opin Cardiol 21: 1-6.

51. Benjamin RM (2011) Dietary guidelines for Americans, 2010: the cornerstone of nutrition policy. Public Health Rep 126: 310-311.

52. Rodriguez NR, Di Marco NM, Langley S (2009) American College of Sports Medicine position stand. Nutrition and athletic performance. Med Sci Sports Exerc 41: 709-731. 